\title{
Effects of High Iodine Containing Low Osmolar Contrast Agent (Visipaque) on Thyroid Function Tests
}

\author{
MAJ Dr. Sorush Niknamian* \\ CEO and Executive Manager of Violet Cancer Institute, Federal Health Professionals and Department of \\ Defense (DoD). VA, USA
}

*Corresponding Authors: MAJ Dr. Sorush Niknamian, CEO and Executive Manager of Violet Cancer Institute, Federal Health Professionals and Department of Defense (DoD). VA, USA.

\begin{abstract}
Objective: Investigating high iodine containing low osmolar contrast agent (visipaque) effects on thyroid function tests and thyroid sonography characteristics.

Methods: 65 euthyroid cases and 92 controls composed the samples in baseline. Thyroid function tests, Urine Iodine Concentration (UIC) and thyroid sonography were conducted for both groups before and 1 and 3 months after angiography. Serum levels of T4,T3,T3RU,TSH,TPO-Ab and UIC were measured, and hypo/hyperthyroidism prevalence was compared between groups.
\end{abstract}

Results: Mean T3, T4 and TSH changes1 month after angiography were insignificant in both groups (P:0.61,P:0.4 and P:0.14, P:0.23 in cases and controls for T3 and T4). Medians among cases and controls were 12.8 and $16.75 \mu \mathrm{g} / \mathrm{dl}$, respectively, at baseline. These values varied to 28.45 and $15.2 \mu \mathrm{g} / \mathrm{dl}$, and 12.95 and $14.2 \mu \mathrm{g} / \mathrm{dll}$ month and 3 months after angiography in case and control groups, respectively.UIC increase one month after angiography was significant among cases $(P=0.002) . T P O-A b+$ were same 3 months after angiography. Thyroid volume changes were significant among cases $(P<0.001)$ and in significant among controls $(P=0.680)$. No significant difference was seen between cases and controls in overt hypothyroidism, however, a considerable change was seen in thyroid volume and UIC one month after an geography among cases. The hypothyroidism rate among cases was insignificant which may be either related to few cases or short half-life of visipaque (2.1 hour) so that 97\% of injected dose was excreted in urine within 24 hours. Conclusion: Thyroid function test is not recommended before angiography in patients without previous thyroid records.

Keywords: Thyroid Disease, Hyperthyroidism, Thyroid function test

\section{INTRODUCTION}

Thyroid diseases are the second most common cause of endocrine disorders following diabetes $(1,2)$. Coronary angiography and angioplasty are important diagnostic and therapeutic procedures for the coronary artery diseases. Iodine containing contrasts which is used in angiography may lead to thyroid dysfunction due to high contents of iodine. Thyroid dysfunction can increase symptomatic coronary artery diseases and cardiovascular mortality (3). Although, another study showed that administration of iodine containing contrast agents which is usually used for coronary angiography on following thyroid hormone concentrations is not companied with hyperthyroidism in patients with normal results of thyroid analysis (4). Medications containing iodinemostly induce thyroid dysfunction.Usual sources of iodine such as antiarrhythmic drugs (amiodarone), eye drops and eye ointments, topical ointments, tooth pastes and multivitamins are disinfectants (5, 6). Although, a case study demonstrated that consumption of high-dose drugs containing iodine can be considered as a predisposed to thyroid dysfunction (7). Iodine containing radio-contrastis the most conventional compounds used in medicine(8).For example, increased ischemic heart diseases, need to cardiac catheterization and CT scans lead to increase in consumption of iodine containing contrasts (9). A single-dose injection for CT-scan releases $7000 \mu \mathrm{g}$ iodine which composes almost 45 folds of needed daily iodine (2). Iodine overload condition can lead to decrease the hormone synthesis in thyroid gland by down regulation of $\mathrm{Na} / \mathrm{I}$ co-transporters(10). However, high amount of iodine intake can impair thyroid regulation and induce thyroid dysfunction (11). Iodine containing contrasts includes 
low-osmolar agents, isosmolar agents and high-osmolar agents. The iso-osmolar and hypo-osmolar agents are suitablefor patients with chronic kidney diseases, although they have higher iodine levels than high-osmolar agents (12).

One study has reported that after radio contrast intake, iodine thyroid pool in normal thyroid remains high up to 4-8 weeks and urinary iodine increases up to $300 \%$ and returns to normal level after 43 days (12). On average, each patient receives about 50-100 cc and 30cc iodine containing contrast in CT-scan and angiography, respectively (13). In angiographic centers,50cc and 30cc of visipaque (Iodixanol) is typically used for CT-angiography and angiography, respectively, (1) as iso-osmolar contrast agent with iodine content of $320 \mathrm{mg} / \mathrm{ml}$.

We investigated the thyroid function tests, thyroid autoimmunity marker (TPOAb), thyroid ultrasonongraphy and urinary iodine in patients undertaking coronary angiography, CT-angiography in Iran, an iodine sufficient area according to WHO reports (12).

\section{Materials ANd Methods}

\subsection{Patients}

This study was performed at angiographic center of Isfahan Endocrine and Metabolism Research Center in 2016-2017.Patients were selected from candidates for coronary angiographic or coronary CT angiography based on continuous enrollment. Inclusion criteria were age over 18 years old, candidate for elective angiography or CT angiography, euthyroid subjects and patient's consent for study. Our study was approved by ethics committee of Isfahan University of Medical Sciences. The medical records include history of previous thyroid diseases or malignancy or taking any medications. Accordingly, history of other disorders such as diabetes, hypertension and dyslipidemia was evaluated. Then, thyroid examination and baseline laboratory tests- including blood and urine samples- were conducted. Next, the thyroid sonography was carried out to evaluate the thyroid and neck soft tissue. The next day, angiography or CT-angiography was done for the case group. The patients were explained by the symptoms of hyperthyroidism or hypothyroidism and they were asked to report any symptoms of hyper/hypothyroidism. The same physical examinations, laboratory tests and thyroid sonography were repeated at 1 and 3 months after angiography or CT-angiography in case and control groups. Data of people enrollment is shown in consort diagram. (Figure 1)

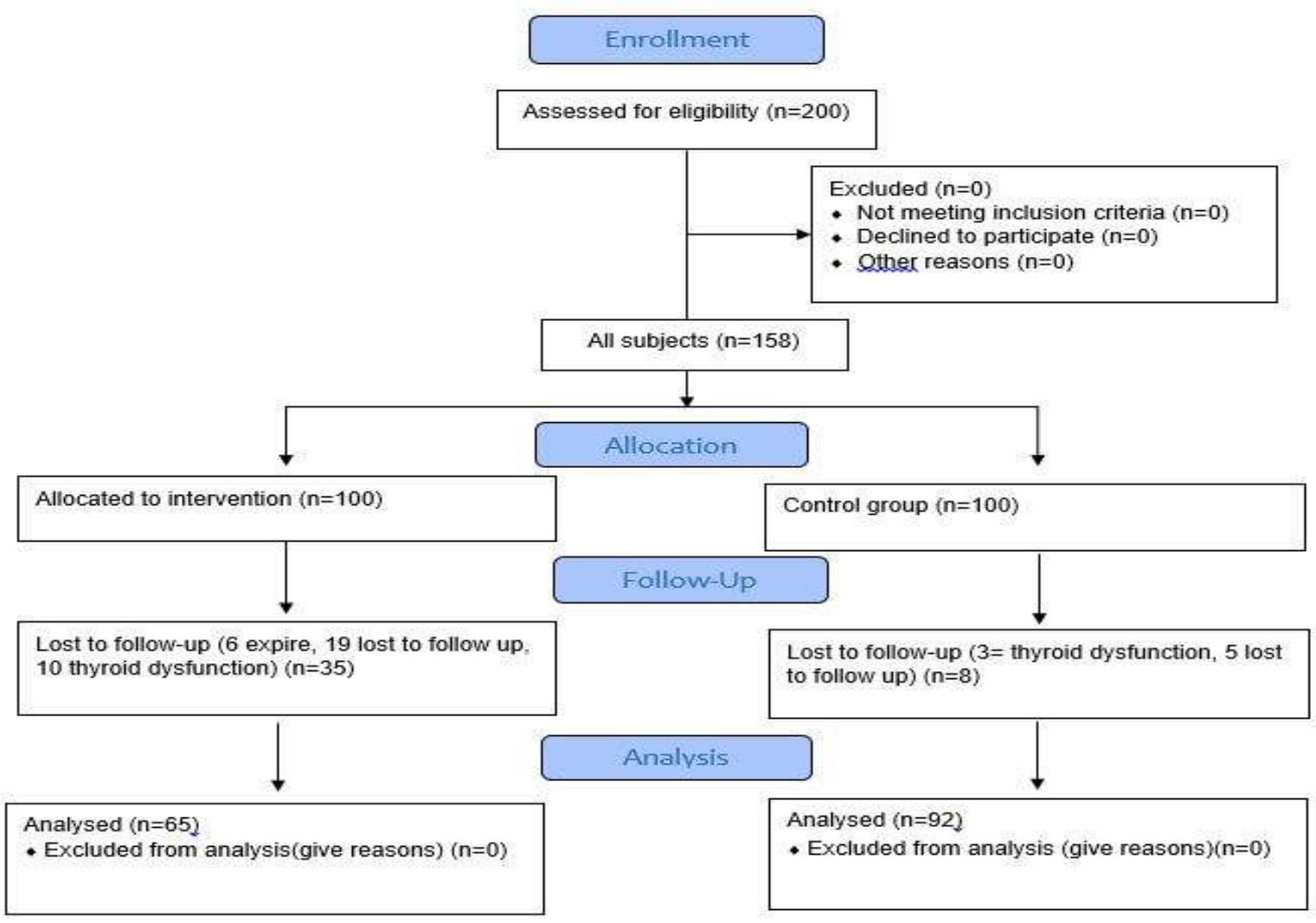

Figure1. Data of people enrollment 


\subsection{Laboratory Studies}

The Fasting Plasma Glucose (FPG), lipid profile include (TG, Cholesterol,LDL-c, HDL-c), Blood Urea Nitrogen $(\mathrm{BUN})$, creatinine $(\mathrm{Cr}) \mathrm{TSH}, \mathrm{T} 4, \mathrm{~T} 3, \mathrm{~T} 3 \mathrm{RU}$, thyroid peroxidase antibody (TPO$\mathrm{Ab}$ ), were determined before coronary angiography.

\subsection{Analytic Approach}

Statistical analysis was performed using SPSS version 24.Descriptive data was presented based on mean, Standard Deviation (SD), frequency, percentage and qualitative data using Chi-square, independent sample T-test and one way-ANOVA for comparing quantitative data between the two groups. ANOVA test was repeated for comparing changes in variables over time within each group or between groups. Median (range) was used for the variables without normal distribution such as UIC. Also, for evaluation of some parameters such as TSH and TPO-Ab that have no normal distribution, we used log-transformation.

\section{RESULTS}

100 patients under the angiography or CT coronary angiography and 100 non-cardiovascular patients were enrolled. During the three month period of follow up, 35 patients in the case group were excluded (Figure 1) and data analysis was done on 65 patients and 92 controls who completed the study. The mean age of case and control groups members was 60.1 and 59.6years, respectively $(\mathrm{p}=0.81) ; 38(58.5 \%)$ of cases and $48(52.2 \%)$ of controls were male $(\mathrm{p}=0.44)$. Demographic characteristics are presented in Table 1.

Table1. Demographic characteristics and baseline values of patients under angiography and control groups

\begin{tabular}{|c|c|c|c|c|}
\hline \multicolumn{2}{|c|}{ Variables $\quad$ groups } & case & Control & $\mathbf{P}$ \\
\hline \multirow{2}{*}{$\begin{array}{l}\text { Sex } \\
\mathrm{N}(\%)\end{array}$} & Male & $38(58.5)$ & $48(52.2)$ & \multirow{2}{*}{0.44} \\
\hline & female & $27(41.5)$ & $44(47.8)$ & \\
\hline \multicolumn{2}{|l|}{ age(year) } & $60.1( \pm 10.3)$ & $59.6( \pm 14)$ & 0.81 \\
\hline \multicolumn{2}{|l|}{ BMI $\left(\mathrm{kg} / \mathrm{m}^{2}\right)$} & $26.88( \pm 3.06)$ & $26.74( \pm 3.94)$ & 0.81 \\
\hline \multicolumn{2}{|c|}{ Family history of thyroid disorders } & $12(18.5)$ & $27(29.3)$ & 0.12 \\
\hline \multicolumn{2}{|c|}{ History of radiotherapy of head and neck } & $3(4.6)$ & $1(1.1)$ & 0.31 \\
\hline \multirow{6}{*}{$\begin{array}{l}\text { Thyroid function } \\
\text { tests at base line }\end{array}$} & $\mathrm{T} 4(\mu \mathrm{g} / \mathrm{dl})$ & $9.11( \pm 2.26)$ & $8.78( \pm 1.58)$ & 0.54 \\
\hline & $\mathrm{T} 3(\mu \mathrm{g} / \mathrm{dl})$ & $1.65( \pm 0.63)$ & $1.7( \pm 0.31)$ & 0.28 \\
\hline & T3RU & $0.9( \pm 0.2)$ & $0.85( \pm 0.12)$ & .056 \\
\hline & TSH (MIU) & $2.84( \pm 2.1)$ & $3.15( \pm 2.95)$ & 0.68 \\
\hline & $\mathrm{TPO} \mathrm{Ab}+$ & $14(21.5 \%)$ & $29(31.5 \%)$ & 0.65 \\
\hline & $\mathrm{UIC}(\mu \mathrm{g} / \mathrm{dl})$ & $12.43( \pm 7.55)$ & $13.54( \pm 8.64)$ & 0.44 \\
\hline
\end{tabular}

T3: three iodothyronin, T4: thyroxin, TSH: thyroid stimulating hormone, T3RU:T3 resin uptake, UIC: urinary iodine concentration, $* P$ value $<0.05$, TPOAb thyroid peroxidase antibody, as considered positive when level $>37 \mathrm{IU} / \mathrm{Ml}$

T3 mean at baseline was $1.65(0.63) \mathrm{nmol} / \mathrm{l}$ and $1.7(0.31) \mathrm{nmol} / \mathrm{l}$ in case and control groups, respectively; it was1.82(0.48)nmol/l and $1.78(0.33) \mathrm{nmol} / \mathrm{l}$ in case and control groups, respectively, one month after angiography; and it was $1.65(0.5) \mathrm{nmol} / \mathrm{l}$ and $1.81(0.13) \mathrm{nmol} / \mathrm{l}$ for case and controls groups three months after angiography; as a result, T3 changes were statistically insignificant in both groups (p:0.61 and p:0.4 in case and control groups). Furthermore, T4 at baseline was 9.11(2.26) $\mu \mathrm{g} / \mathrm{dl}$ and 8.78(1.58) $\mu \mathrm{g} / \mathrm{dl}$ in case and control groups; it varied to9.15 $(2.16) \mu \mathrm{g} / \mathrm{dl}$ and $8.62(1.48) \mu \mathrm{g} / \mathrm{dl} 1$ month after angiography and also 8.76( 1.89) $\mu \mathrm{g} / \mathrm{dl}$ and $8.83(6.15) \mu \mathrm{g} / \mathrm{dl}$ three months after angiography in case and control groups respectively, indicating no significant change (P:0.07 and P:0.8 for case and control groups). Baseline TSH among cases and controls was $2.84(2.1) \mu \mathrm{u} / \mathrm{ml}$ and $3.15(2.95) \mu \mathrm{u} / \mathrm{ml}$, respectively; it varied to $2.98(1.06) \mu \mathrm{u} / \mathrm{ml}$ and $3.22(2.39) \mu \mathrm{u} / \mathrm{ml} 1$ month later and $4.14(1.5) \mu \mathrm{u} / \mathrm{ml}$ and $3.49(2.58) \mu \mathrm{u} / \mathrm{ml} 3$ months later in case and control groups, respectively, indicating no significant TSH changes (P:0.14 and P:0.23 among cases controls). (Table 2).

The mean of serum TSH, T4, T3 and TPOAb concentrations in different thyroid functions are presented in (Tables 3a and 3b). Mean of serum TSH level was statistically increased in one month after study in both groups but other functional thyroid hormones (T3 and T4) were not different among exposed and non-exposed groups. Moreover, 14 cases and 28 controls were become hypothyroid (mild and overt hypothyroidism) and no statistically significant difference was seen between the two groups $(\mathrm{p}=0.07)$. 
Effects of High Iodine Containing Low Osmolar Contrast Agent (Visipaque) on Thyroid Function Tests

Table2. The mean changes of thyroid function test in the before and after angiography In the two groups

\begin{tabular}{|c|c|c|c|c|c|}
\hline variables & Groups & Baseline & $\mathbf{1}^{\text {st }}$ month & $\mathbf{3}^{\text {rd }}$ months & P \\
\hline \multirow{2}{*}{$\mathrm{T} 4(\mu \mathrm{g} / \mathrm{dl})$} & Case & $9.11(2.26)$ & $9.15(2.16)$ & $8.76(1.89)$ & 0.07 \\
\cline { 2 - 6 } & control & $8.78(1.58)$ & $8.62(1.48)$ & $8.83(6.15)$ & 0.8 \\
\hline \multirow{2}{*}{$\mathrm{T} 3(\mathrm{nmol} / \mathrm{l})$} & Case & $1.65(0.63)$ & $1.82(0.48)$ & $1.65(0.5)$ & 0.61 \\
\cline { 2 - 6 } & control & $1.7(0.31)$ & $1.78(0.33)$ & $1.81(.13)$ & 0.4 \\
\hline \multirow{2}{*}{$\mathrm{T} 3 \mathrm{RU}(\mu \mathrm{u} / \mathrm{ml})$} & Case & $2.84(2.1)$ & $2.98(1.06)$ & $4.14(1.5)$ & 0.14 \\
\cline { 2 - 6 } & control & $3.15(2.95)$ & $3.22(2.39)$ & $3.49(2.58)$ & 0.23 \\
\hline \multirow{2}{*}{$\begin{array}{c}\mathrm{TSH} \text { median } \\
(\text { range) }\end{array}$} & Case & $1.7(1.2-3)$ & $1.8(1.2-3.35)$ & $2.3(1.5-3.2)$ & $0.027^{*}$ \\
\cline { 2 - 6 } & control & $2.3(1.43-3.1)$ & $2.5(1.93-3.5)$ & $2.55(1.8-4.2)$ & $0.009^{*}$ \\
\hline
\end{tabular}

*mean $\pm S D$;*median (percentile25-75); T3: three iodothyronin, T4: 1thyroxin, TSH: thyroid stimulating hormone; $*$ value $<0.05$

Table3a. Thyroid function tests 1 month after exposure

\begin{tabular}{|l|c|c|c|c|c|c|c|c|}
\hline \multirow{2}{*}{ Scale } & \multicolumn{4}{|c|}{ Case group } & \multicolumn{4}{c|}{ Control group } \\
\cline { 2 - 10 } & $\begin{array}{c}\text { Euthyroid } \\
(\mathrm{n}=51)\end{array}$ & $\begin{array}{c}\text { Mild Hypo } \\
(\mathrm{n}=10)\end{array}$ & $\begin{array}{c}\text { Overt-hypo } \\
(\mathrm{n}=4)\end{array}$ & $\mathrm{P}$ & $\begin{array}{c}\text { Euthyroid } \\
(\mathrm{n}=64)\end{array}$ & $\begin{array}{c}\text { Mild Hypo } \\
(\mathrm{n}=24)\end{array}$ & $\begin{array}{c}\text { Overt-hypo } \\
(\mathrm{n}=4)\end{array}$ & $\mathrm{P}$ \\
\hline $\mathrm{T} 3(\mathrm{nmol} / \mathrm{l})$ & $1.8(0.4)$ & $1.7(.55)$ & $1.9(51)$ & 0.74 & $1.8(0.31)$ & $1.4(0.35)$ & $1.35(.35)$ & 0.14 \\
\hline $\mathrm{T} 4(\mu \mathrm{g} / \mathrm{dl})$ & $9.8(6.7)$ & $9.5(5.5)$ & $13.8(5.9)$ & 0.12 & $9.1(3.9)$ & $8.8(6.5)$ & $9.04(6.3)$ & 0.06 \\
\hline $\mathrm{TSH}(\mu \mathrm{u} / \mathrm{l})$ & $1.8(0.8)$ & $8.2(1.6)$ & $13.7(2.5)$ & $<0.001$ & $2.3(0.6)$ & $5.6(1.7)$ & $14.6(0.8)$ & $<0.001$ \\
\hline $\mathrm{T} 3 \mathrm{RU}$ & $0.96(0.1)$ & $1.03(0.3)$ & $0.7(0.1)$ & 0.08 & $0.9(0.1)$ & $0.92(0.2)$ & $0.7(0.001)$ & 0.12 \\
\hline $\mathrm{N}(\%) \mathrm{TPO}+$ & $10(19.6 \%)$ & $3(30 \%)$ & $1(25 \%)$ & 0.66 & $20(31 \%)$ & $8(33.3 \%)$ & $1(2 \%)$ & 0.43 \\
\hline $\mathrm{UIC}(\mu \mathrm{g} / \mathrm{dl})$ & $29.68(14.2)$ & $26.93(17.6)$ & $27.9(3.3)$ & 0.93 & $29.4(14.2)$ & $18.6(10.9)$ & $14.7(9.7)$ & 0.44 \\
\hline
\end{tabular}

T3: three iodothyronin, T4: thyroxin, TSH: thyroid stimulating hormone, TPOAb thyroid peroxidase antibody, as considered positive when level >37 IU/Ml, T3RU:T3 resin uptake, *P value <0.05, UIC: urinary iodine concentration

Table3b. Thyroid function tests 3 month after exposure

\begin{tabular}{|l|c|c|c|c|c|c|c|c|}
\hline \multirow{2}{*}{ Scale } & \multicolumn{4}{|c|}{ Case group } & \multicolumn{4}{c|}{ Control group } \\
\cline { 2 - 9 } & $\begin{array}{c}\text { Euthyroid } \\
(\mathrm{n}=51)\end{array}$ & $\begin{array}{c}\text { Mild Hypo } \\
(\mathrm{n}=10)\end{array}$ & $\begin{array}{c}\text { Overt-hypo } \\
(\mathrm{n}=4)\end{array}$ & $\mathrm{P}$ & $\begin{array}{c}\text { Euthyroid } \\
(\mathrm{n}=64)\end{array}$ & $\begin{array}{c}\text { Mild Hypo } \\
(\mathrm{n}=24)\end{array}$ & $\begin{array}{c}\text { Overt-hypo } \\
(\mathrm{n}=4)\end{array}$ & $\mathrm{P}$ \\
\hline T3 & $1.67(0.48)$ & $1.58(0.48)$ & $1.6(0.26)$ & 0.82 & $1.7(0.5)$ & $2.1(2)$ & $1.5(0.27)$ & 0.28 \\
\hline T4 & $9.2(1.8)$ & $7.3(1)$ & $6.6(0.5)$ & $<0.1$ & $8.3(1.7)$ & $10.6(2.9)$ & $7.5(1.5)$ & 0.27 \\
\hline TSH & $1.95(0.8)$ & $6.2(1.7)$ & $27(8.6)$ & $<0.001$ & $2.2(0.7)$ & $5.2(1.5)$ & $14.2(2.1)$ & $<0.001$ \\
\hline TTRU & $0.93(0.1)$ & $0.88(0.15)$ & $0.85(0.1)$ & 0.19 & $0.9(0.1)$ & $0.9(0.2)$ & $0.87(0.1)$ & 0.95 \\
\hline N (\%) TPO + & $11(21.6 \%)$ & $3(30 \%)$ & $1(25 \%)$ & 0.84 & $18(28.1 \%)$ & $8(33.3 \%)$ & $2(50 \%)$ & 0.61 \\
\hline UIC & $17.8(11.7)$ & $7.1(2.1)$ & $17.4(11.7)$ & 0.38 & $13(5)$ & $14.1(5.7)$ & $17.8(10.1)$ & 0.57 \\
\hline
\end{tabular}

T3: three iodothyronin, T4: thyroxin, TSH: thyroid stimulating hormone, TPO-Ab thyroid peroxidase antibody, as considered positive when level >37 IU/Ml, T3RU:T3 resin uptake, *P value <0.05, UIC: urinary iodine concentration

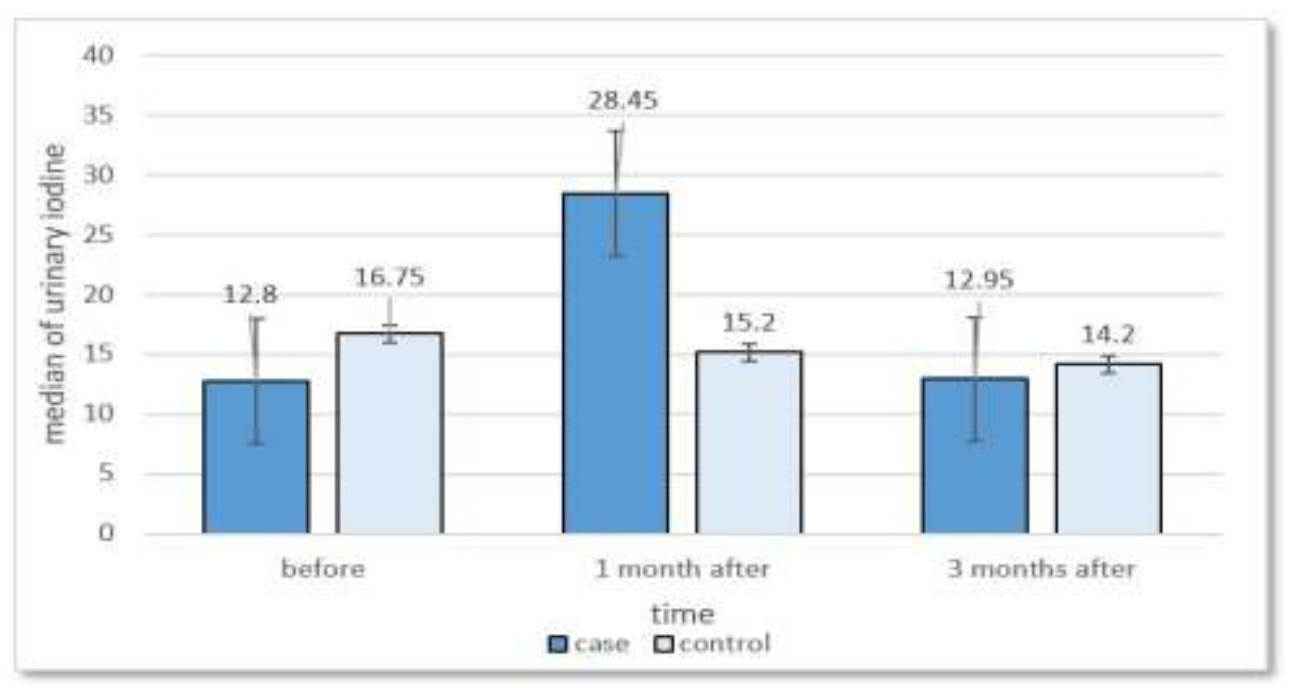

Figure2. Distribution of TSH level (including range, median and 25-75 percentile) in 1 and 3 months after intervention 
Also the mean level of TSH was not different between the case and control groups in 1 and 3 months after intervention. Distribution of TSH level (including range, median and 25-75 percentile) in 1 and 3 months after intervention are shown in Figure 2.

In addition, frequency of TPO-Ab+ in case and control group was 14 and 29 (21.5\% VS 31.5), respectively, and no statistically difference was found between the two groups $(\mathrm{P}=0.17)$.

Median of urinary iodine was not different between exposed and non-exposed groups at baseline( $\mathrm{P}=0.93)$ as well as 1 and 3 months after intervention (Figure 2).Median of urinary iodine before exposure was $12.8 \mu \mathrm{g} / \mathrm{dl}$ and $16.75 \mu \mathrm{g} / \mathrm{dl}$ among cases and controls, respectively, indicating no statistically significant difference between two groups $(\mathrm{p}=0.059)$. Median of urinary iodine one month after exposure was $28.45 \mu \mathrm{g} / \mathrm{dl}$ and $15.2 \mu \mathrm{g} / \mathrm{dl}$ among cases and controls, respectively, indicating a statistically significant difference between the two groups $(\mathrm{p}=0.002)$; while it was $12.95 \mu \mathrm{g} / \mathrm{dl}$ and $14.2 \mu \mathrm{g} / \mathrm{dl}$ among cases and controls, respectively, 3 months after exposure, indicating no statistically significant difference between the two group ( $\mathrm{p}=0.13$ ) (Figure 3).

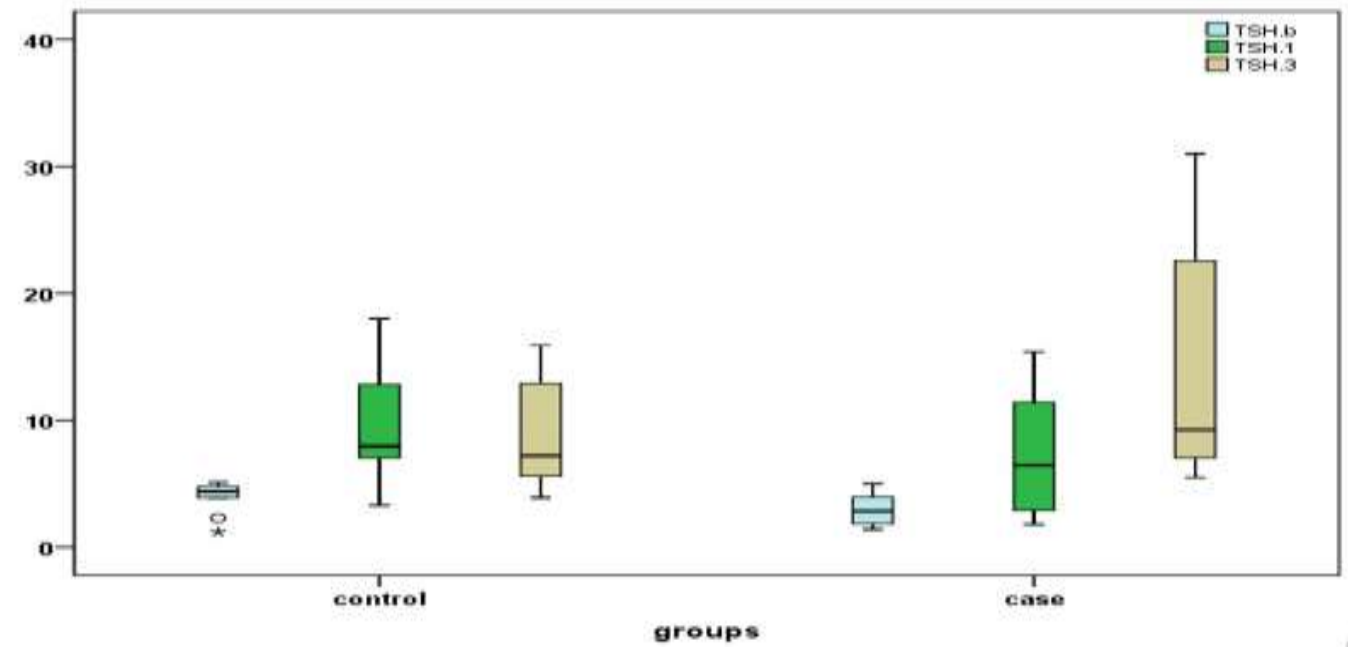

Figure3. Median, range and 25-75 percentile of TSH level in hypothyroid patients in the case and control groups

Mean value of thyroid volume in case group at baseline was 5.908(1.36-8.8)cc which increased to 6.244.7(1.039.6)cc one month later and decreased to $5.630(1.323) \mathrm{cc}$ three months later. Thyroid volume changes in case group were statistically significant $(\mathrm{P}<0.001)$ but they were insignificant among the controls $(\mathrm{P}=0.680) \mathrm{cc}$. Similarly, mean thyroid volume at baseline was 5.611.9(1.477.6)cc and it was 5.662(1.394)cc and 5.639(1.403)cc one and three months later, respectively, respectively (Tables 4 and 5).

Table4. Mean changes of thyroid volume $\left(\mathrm{mm}^{3}\right)$ in the two groups

\begin{tabular}{|l|c|c|}
\hline \multirow{2}{*}{ Time } & \multicolumn{2}{c|}{ Groups } \\
\cline { 2 - 3 } & case & control \\
\hline Baseline & $5908.6 \pm 1368.8$ & $5611.9 \pm 1477.6$ \\
\hline 1 month later & $6244.7 \pm 1039.6$ & $5662 \pm 1394$ \\
\hline 3 months later & $5630 \pm 1323$ & $5639.9 \pm 1403$ \\
\hline $\mathrm{P}$ & $<0.001$ & 0.68 \\
\hline
\end{tabular}

Table5. Mean thyroid volume (CC) based on thyroid status in case and control groups in1 and 3 months after exposure

\begin{tabular}{|c|c|c|c|}
\hline \multirow{2}{*}{ Time } & Thyroid volume & \multicolumn{2}{|c|}{ Groups } \\
\cline { 2 - 4 } & & case & control \\
\hline \multirow{3}{*}{ One month after } & Normal & $6.403 .(0950)$ & $5675.7(1353.3)$ \\
\cline { 2 - 4 } & Mild hypo & $5.725(1018)$ & $5515.8(1947.6)$ \\
\cline { 2 - 4 } & Overt & $4.326 .9(383.4)$ & $5603(1929)$ \\
\cline { 2 - 4 } & $\mathrm{P}$ & 0.001 & 0.96 \\
\hline \multirow{3}{*}{ three months after } & Normal & $5.762 .3(1334.9)$ & $6529.3(1364.7)$ \\
\cline { 2 - 4 } & Mild hypo & $4.092 .4(493.1)$ & $5873.6(1492.1)$ \\
\cline { 2 - 4 } & Overt & 0.044 & $5046(1813.9)$ \\
\cline { 2 - 4 } & $\mathrm{P}$ & & 0.62 \\
\hline
\end{tabular}




\section{DISCUSSION}

The patients with cardiovascular diseases usually considerably need angiography and angioplasty for management of coronary disease, which lead to exposure to iodine containing contrast media and cause some problems for such patients such as congestive heart failure and cardiac arrhythmia (2).It is also reported that contrast agents increase thyroid dysfunction such as hyperthyroidism and hypothyroidism(14), and cardiopulmonary arrest after radio-contrasts injection (15).The result from a large epidemiological study in Iran showed this country as an endemic iodine deficient area (16).

Our results showed the mean urine iodine as 20/3mg and 20/1 mg/d for Euthyroid and hypothyroid subjects, respectively, (16) and in a study conducted in Isfahan, the UIC median for iodine sufficiency is reported $18 \mu \mathrm{g} / \mathrm{dl}$ (20).It is also shown that contrast medias are independent risk factors for mortality and cardiovascular events (17). Also, in a prospective cohort conducted on 101 euthyroid patients, hyperthyroidism was arisen among such these patients (18). Additionally, evaluation of thyroid function tests 1,3,6,12 months after angiography indicate several new cases of hyperthyroidism where severity of baseline thyroid dysfunction is increased (19).Some studies found no finding about any effect or significant change in thyroid function tests(20). Due to different results of studies and lack of similar study in Iran, we decided to evaluate effect of contrast agents on thyroid function tests as our main goal. Previous studies have not investigated thyroid sonographic features and UIC and their association with thyroid dysfunction. In our study, no significant difference was found in terms of mean changes of T4 $(\mathrm{P}=0.47)$, total T3 $(\mathrm{P}=0.7)$ and TSH $(\mathrm{P}=0.95)$ between the two groups. Median of UIC was $12.8 \mu \mathrm{g} / \mathrm{dl}$ and $16.75 \mu \mathrm{g} / \mathrm{dl}$ among cases and controls, respectively, at baseline; and it increased to $28.45 \mu \mathrm{g} / \mathrm{dl}$ and $15.2 \mu \mathrm{g} / \mathrm{dl}$ and also $12.95 \mu \mathrm{g} / \mathrm{dl}$ and $14.2 \mu \mathrm{g} / \mathrm{dl}$ one and three months after intervention, respectively, among cases in controls, indicating a statistically significant change after one month $(\mathrm{P}=0.002)$. Mean values of $\mathrm{TPO}-\mathrm{Ab}+$ three months after angiography were same as the baseline. Thyroid volume changes in case group were statistically significant $(\mathrm{P}<0.001)$ while they were insignificant among controls $(\mathrm{P}=0.680)$. There was no significant difference between case and control group in overt hypothyroidism while a significant difference was seen in terms of thyroid volume and size and UIC one month after angiography in both groups. Consequently, the use of iodine containing contrast media in angiography in cardiovascular diseases may be associated with thyroid dysfunction and cardiac dysfunctions such as cardiac arrhythmia among such patients, this is why we were motivated for this study. Among the patients, we found some insignificant changes in thyroid volume and mean TSH level among members of exposed group, therefore, follow up of thyroid function tests among euthyroid patients is not recommended.

\section{CONCLUSION}

In conclusion, thyroid volume changes were significant among cases $(\mathrm{P}<0.001)$ and insignificant among controls $(\mathrm{P}=0.680)$. No significant difference was seen between cases and controls in overt hypothyroidism, however, a considerable change was seen in thyroid volume and UIC one month after angiography among cases. The hypothyroidism rate among cases was insignificant which may be either related to few cases or short half-life of visipaque (2.1 hour).

\section{REFERENCES}

[1] Aminorroaya A, Meamar R, Amini M, Feizi A, Tabatabae A, Imani EF. Incidence of thyroid dysfunction in an Iranian adult population: the predictor role of thyroid autoantibodies: results from a prospective population-based cohort study. European Journal of Medical Research. 2017;22(1):21.

[2] Canaris GJ, Manowitz NR, Mayor G, Ridgway EC. The Colorado thyroid disease prevalence study. Archives of internal medicine. 2000;160(4):526-34.

[3] Cappola AR, Fried LP, Arnold AM, Danese MD, Kuller LH, Burke GL, et al. Thyroid status, cardiovascular risk, and mortality in older adults. Jama. 2006;295(9):1033-41.

[4] Koroscil M, PhD, Thomas M, Pelletier M, Peter R, Slauson M, James W, Hennessey M, James. Short-term effects of coronary angiographic contrast agents on thyroid function. Endocrine Practice. 1997;3(4):21921.

[5] Thomsen HS, Faber J. Iodine-based contrast media cause hyperthyroidism-another important adverse reaction to contrast media? : SAGE Publications; 2012.

[6] Seminara M, Stephanie B, Daniels M, FACE, Gilbert H. Amiodarone and the thyroid. Endocrine Practice. 1998;4(1):48-57. 
[7] Hoang T, Mai V, Clyde P, Shakir M. Over-the-counter-drug-induced thyroid disorders. Endocrine Practice. 2013;19(2):268-74.

[8] Toprak O, Cirit M, Bayata S, Yeşil M. Review of the radiocontrast nephropathy risk profiles and risk stratification. Anadolu kardiyoloji dergisi: $\mathrm{AKD}=$ the Anatolian journal of cardiology. 2004;4(4):331-5.

[9] Katzberg R, Haller C. Contrast-induced nephrotoxicity: clinical landscape. Kidney International. 2006;69:S3-S7.

[10] Eng PH, Cardona GR, Fang S-L, Previti M, Alex S, Carrasco N, et al. Escape from the acute WolffChaikoff effect is associated with a decrease in thyroid sodium/iodide symporter messenger ribonucleic acid and protein. Endocrinology. 1999;140(8):3404-10.

[11] Zimmermann MB, Aeberli I, Torresani T, Bürgi H. Increasing the iodine concentration in the Swiss iodized salt program markedly improved iodine status in pregnant women and children: a 5-y prospective national study. The American journal of clinical nutrition. 2005;82(2):388-92.

[12] Lee SY, Rhee CM, Leung AM, Braverman LE, Brent GA, Pearce EN. A review: Radiographic iodinated contrast media-induced thyroid dysfunction. The Journal of Clinical Endocrinology \& Metabolism. 2015;100(2):376-83.

[13] Mann DL, Felker GM. Heart Failure E-Book: A Companion to Braunwald's Heart Disease: Elsevier Health Sciences; 2014.

[14] Kornelius E, Chiou J-Y, Yang Y-S, Peng C-H, Lai Y-R, Huang C-N. Iodinated contrast media increased the risk of thyroid dysfunction: A 6-year retrospective cohort study. The Journal of Clinical Endocrinology \& Metabolism. 2015;100(9):3372-9.

[15] Alkhuja S, Pyram R, Odeyemi O. In the eye of the storm: Iodinated contrast medium induced thyroid storm presenting as cardiopulmonary arrest. Heart \& Lung: The Journal of Acute and Critical Care. 2013;42(4):267-9.

[16] Azizi F, Hatami H, Janghorbani M. Epidemiology and control of common diseases in Iran. Tehran: Eshtiagh Publications. 2000:602-16.

[17] Marraccini P, Bianchi M, Bottoni A, Mazzarisi A, Coceani M, Molinaro S, et al. Prevalence of thyroid dysfunction and effect of contrast medium on thyroid metabolism in cardiac patients undergoing coronary angiography. Acta Radiologica. 2013;54(1):42-7.

[18] Ozkan S, Oysu AS, Kayatas K, Demirtunç R, Eren M, Uslu H, et al. Thyroid functions after contrast agent administration for coronary angiography: a prospective observational study in euthyroid patients. Anadolu Kardiyol Derg. 2013;13(4):363-9.

[19] Egorov V, Sviridenko N, Platonova N, Arbuzova M, Zlotnikova O, Buziashvili I, et al. Disturbances of thyroid function after coronary angiography. Kardiologiia. 2005;46(4):46-9.

[20] van der Molen AJ, Thomsen HS, Morcos SK, Radiology MoCMSCoESoU. Effect of iodinated contrast media on thyroid function in adults. European radiology. 2004;14(5):902-7.

Citation: MAJ Dr. Sorush Niknamian, "Effects of High Iodine Containing Low Osmolar Contrast Agent (Visipaque) on Thyroid Function Tests", International Journal of Research Studies in Biosciences, 8(6), pp. 18-24. DOI: https:// doi.org/10.20431/2349-0365.0806005

Copyright: (C) 2020 Authors, This is an open-access article distributed under the terms of the Creative Commons Attribution License, which permits unrestricted use, distribution, and reproduction in any medium, provided the original author and source are credited. 